\title{
Characterization and description of a multiple sex chromosome system in Potamotrygon motoro (Chondrichthyes, Myliobatiformes) from the Paraná River, Argentina
}

\author{
D.R. Aichino ${ }^{1}$, M.C. Pastori $^{1}$, H.A. Roncati ${ }^{1}$, M.A. Ledesma ${ }^{2}$, A.C. Swarça $^{3}$ \\ and A.S. Fenocchio ${ }^{1}$ \\ ${ }^{1}$ Departamento de Genetica, Facultad de Ciencias Exactas, \\ Químicas y Naturales, Universidad Nacional de Misiones, \\ Posadas, Misiones, Argentina \\ ${ }^{2}$ Ministério de Ecologia, Posadas, Misiones, Argentina \\ ${ }^{3}$ Departamento de Histologia, Centro de Ciências Biológicas, \\ Universidade Estadual de Londrina, Londrina, PR, Brasil \\ Corresponding author: A.C. Swarça \\ E-mail: swarca@uel.br \\ Genet. Mol. Res. 12 (3): 2368-2375 (2013) \\ Received July 30, 2012 \\ Accepted November 25, 2012 \\ Published January 16, 2013 \\ DOI http://dx.doi.org/10.4238/2013.January.16.3
}

\begin{abstract}
The Potamotrygonidae family represents the only freshwater group of specialized elasmobranchs and is composed of 4 genera: Plesiotrygon, Paratrygon, Potamotrygon, and Heliotrygon. Individuals of Potamotrygon motoro were collected from the Paraná River at Ituzaingó (Province of Corrientes) in Argentina. Mitotic preparations were obtained using direct techniques and lymphocyte cultures. Chromosomes were studied with conventional Giemsa, $\mathrm{C}$-band and nucleolus organizer region stainings. The diploid number and karyotype formulae were $2 \mathrm{n}=66$ with 33 homomorphic pairs $(14 \mathrm{M}+16 \mathrm{SM}+22 \mathrm{ST}+14 \mathrm{~A})$ in females and $2 \mathrm{n}=65$ with 31 homomorphic pairs plus 3 heteromorphic chromosomes $(13 \mathrm{M}+$ $15 \mathrm{SM}+23 \mathrm{ST}+14 \mathrm{~A}$ ) in males. Heterochromatin was distributed at
\end{abstract}


the pericentromeric regions of almost all chromosomes and in the telomeric and interstitial positions of some chromosomes. nucleolus organizer regions were multiple and located at telomeric regions. Because of the clear karyotype differences between the 2 sexes and the presence of 3 unpaired chromosomes in males, it is possible to suggest the occurrence of a multiple sex chromosome system, with male heterogamety $\left(\mathrm{X}_{1} \mathrm{X}_{1} \mathrm{X}_{2} \mathrm{X}_{2} / \mathrm{X}_{1} \mathrm{X}_{2} \mathrm{Y}\right)$. Further cytogenetic studies are required to develop a hypothesis about the origin of the multiple sex chromosome system in P. motoro.

Key words: Potamotrygon motoro; Neotropical region; Chondrichthyes; Cartilaginous fishes; Sex chromosomes

\section{INTRODUCTION}

River stingrays are Neotropical freshwater fishes of the Potamotrygonidae family and they represent the only group of specialized elasmobranchs (Brooks et al., 1981; Lovejoy, 1996). There remains much debate about whether they belong to the Rajiformes (Castex, 1964; López et al., 2003) or Myliobatiformes order (Mould, 1997; Carvalho et al., 2004; Martin, 2004; Menni, 2004). In the present study, the classification of Carvalho et al. (2004) was adopted. Four potamotrygonid genera are currently recognized: Paratrygon Duméril, 1865; Potamotrygon Garman, 1877; Plesiotrygon Rosa, Castello, and Thorson, 1987 (Rosa et al., 1987; Carvalho et al., 2003), and the recently described Heliotrygon (Carvalho and Lovejoy, 2011).

Potamotrygon is the most diverse genera with approximately 20 valid species (Carvalho and Lovejov, 2011; Silva and Carvalho, 2011). This group is distributed along the rivers of South America that drain into the Atlantic Ocean and Caribbean Sea (Nelson, 1994), with the exception of São Franciso River and the streams in the south of La Plata River (Brooks et al., 1981).

In Argentina, the occurrence of 6 or 7 Potamotrygon species was proposed (Carvalho et al., 2003; López et al., 2003), with P. motoro (Müller and Henle, 1841) having the largest geographic distribution (Castex, 1964; Martinez-Achenbach and Valentinis, 1976). This species of stingray is commonly called raya, yabebuí, or arraya.

Cytogenetic knowledge on Chondrichthyes remains sparse, with just 70 species having been karyotyped out of more than 1100 described species. Such analyses showed that these vertebrates have peculiarities associated with the karyotypes and the size and composition of their DNA (Stingo and Roco, 1991, 2001). Although the data for this group remain fragmentary, there appears to be more differences than similarities with teleosts. For instance, chromosome sets are characterized by a high diploid number $(2 n=$ up to 106) and are often rich in acrocentric elements and microchromosomes (Stingo and Roco, 1991).

To date, few species of the family Potamotrygonidae have been studied cytogenetically. The species include: Paratrygon aiereba $(2 \mathrm{n}=90)$, P. motoro $(2 \mathrm{n}=66)$, and Potamotrygon orbignyi $(2 \mathrm{n}=66)$, which were collected from middle Negro River, AM, Brazil, without sex chromosome heteromorphism (de Valentim et al., 2006). However, the occurrence of an 
$\mathrm{X}_{1} \mathrm{X}_{1} \mathrm{X}_{2} \mathrm{X}_{2} / \mathrm{X}_{1} \mathrm{X}_{2} \mathrm{Y}$ multiple sex chromosome system has been reported in $P$. aff. motoro and $P$. falkneri from the upper Paraná River basin, Brazil, with $2 n=66$ chromosomes for the females and $2 \mathrm{n}=65$ chromosomes for the males of both species (Cruz et al., 2011).

Most Neotropical fishes do not have morphologically differentiated sexual chromosomes, and according to Oliveira et al. (2009), only 5.9\% of the species studied cytogenetically have simple sex chromosomes, with female heterogamety. In marine Myliobatiformes, the few described cases of chromosomal systems for sexual determination are simple, with male heterogamety. However, chromosomal heteromorphisms related to sex have not been reported in Rajiformes (Maddock and Schwartz, 1996; Stingo and Rocco, 2001).

In the present study, specimens of $P$. motoro from the Paraná River (Argentina) were cytogenetically analyzed for the first time.

\section{MATERIAL AND METHODS}

Fifteen individuals of P. motoro ( 8 females and 7 males) were collected from the Paraná River at Ituzaingo and Garapé (Province of Corrientes, Argentina), as well as near Posadas (Province of Misiones, Argentina). This geographic area is located in the "Ecorregión Ictiológica Misionera" and the "Axis Potámico Subtropical” (López et al., 2002).

Mitotic preparations were obtained using direct techniques (Bertollo et al., 1978) and lymphocyte cultures (Fenocchio and Bertollo, 1988). C-bands and Ag nucleolus organizer regions (Ag-NORs) were obtained according to the methods used by Sumner (1972) and Howell and Black (1980), respectively. Chromosome types were determined according to the method described by Guerra (1986), and the karyotypes were organized in decreasing order of size, being classified as metacentrics (M), submetacentrics (SM), subtelocentrics (ST), and acrocentrics (A). The fundamental number (FN) was obtained by assuming that the M, SM, and ST chromosomes were bi-armed and that the A chromosomes were mono-armed.

\section{RESULTS}

The diploid number obtained by counting 286 female cells and 118 male cells was $2 \mathrm{n}$ $=66$ and $2 \mathrm{n}=65$, respectively (Figure $1 \mathrm{~A}$ and $\mathrm{B}$ ). The karyotype formula showed 33 homomorphic pairs in the females $(14 \mathrm{M}+16 \mathrm{SM}+22 \mathrm{ST}+14 \mathrm{~A})$, with an $\mathrm{FN}=118$ (Figure 1A). The males had 31 homomorphic pairs, plus 3 heteromorphic chromosomes $(13 \mathrm{M}+15 \mathrm{SM}+$ $23 \mathrm{ST}+14 \mathrm{~A}$ ) and an $\mathrm{FN}=116$. Two of these elements might be homologues of the pairs $5(\mathrm{M})$ and $15(\mathrm{SM})$ of the females and were termed " $\mathrm{X}_{1}$ " and " $\mathrm{X}_{2}$ ", respectively. The large additional unpaired ST element was termed "Y" (Figure 1B).

Heterochromatin was distributed at the pericentromeric regions along almost all chromosomes and in the telomeric and interstitial positions of some chromosomes. The arms of the 19th pair were completely C-positive stained (Figure 2A and B). The Y chromosome of the males had a distinctive feature: a large heterochromatic band in the pericentromeric region (Figure 2B). The other sex-related chromosomes $\left(\mathrm{X}_{1} \mathrm{X}_{2}\right.$ in the males and $\mathrm{X}_{1} \mathrm{X}_{1} / \mathrm{X}_{2} \mathrm{X}_{2}$ in the females) exhibited pericentromeric C-positive bands.

The NORs were multiple and were identified from 4 to 6 chromosomes stained with silver salts $\left(\mathrm{AgNO}_{3}\right)$ that showed the presence of bands at the telomeric regions (Figure 3). 
A

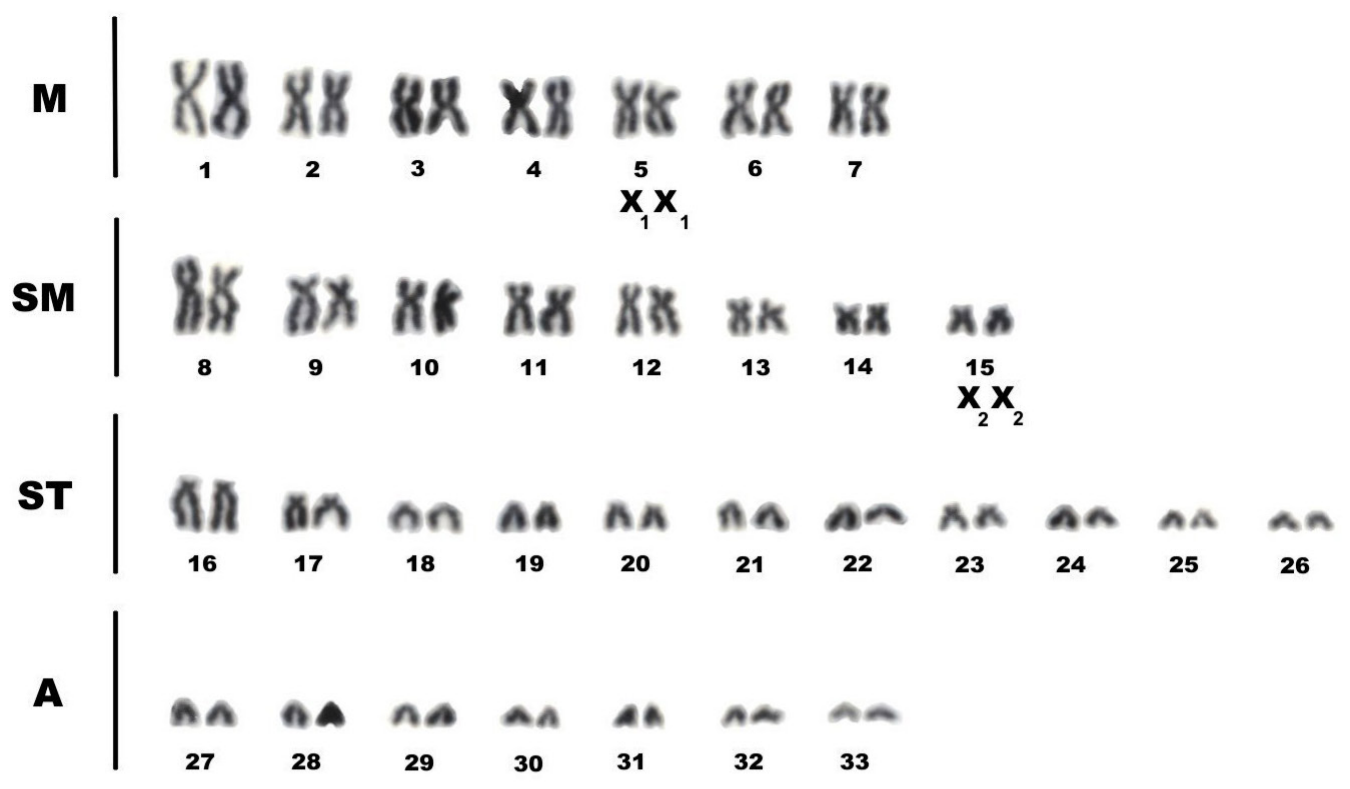

B

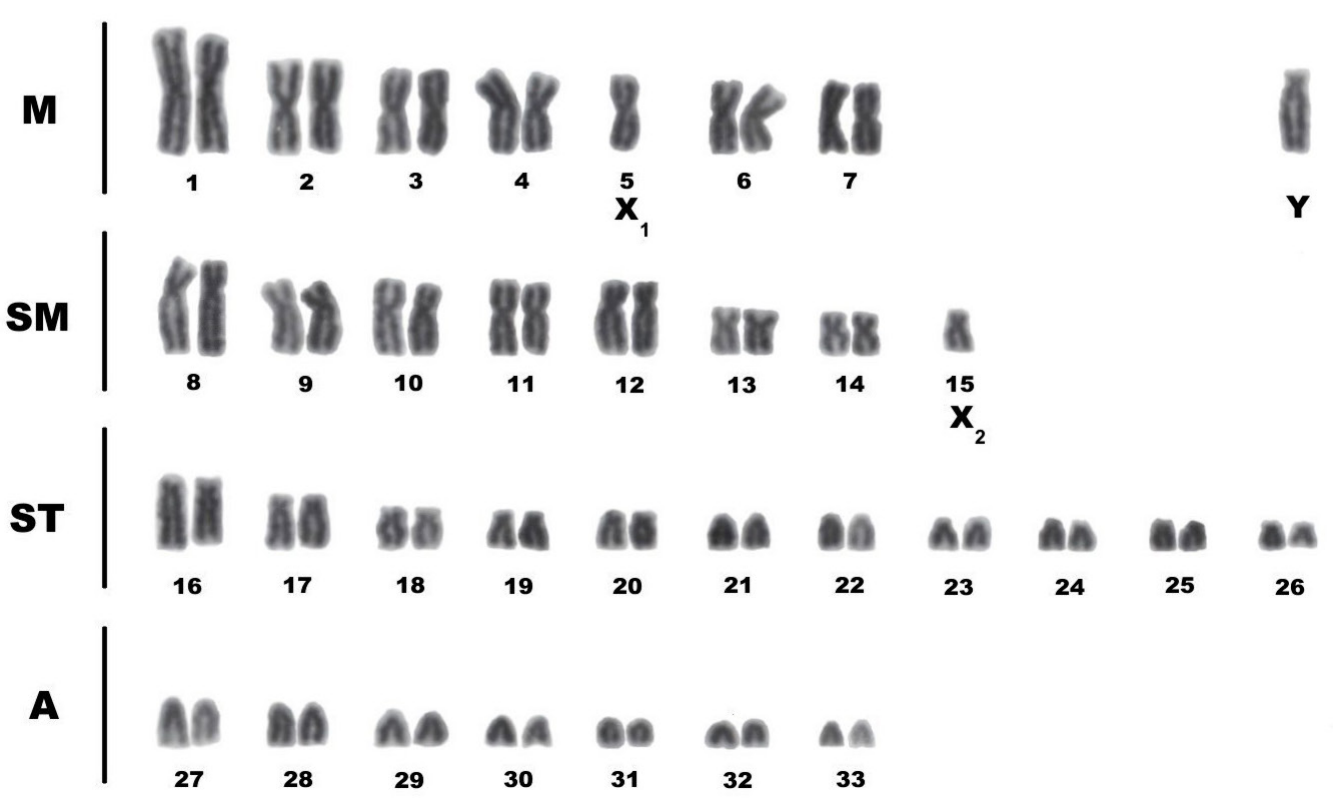

Figure 1. Karyotype of Potamotrygon motoro. A. Females; B. males. $M=$ metacentrics; $\mathrm{SM}=$ submetacentrics; ST $=$ subtelocentrics; $\mathrm{A}=$ acrocentrics. 
A

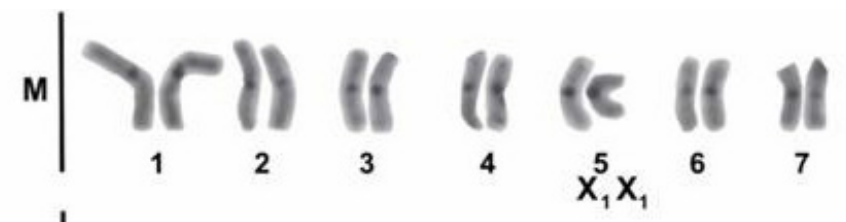

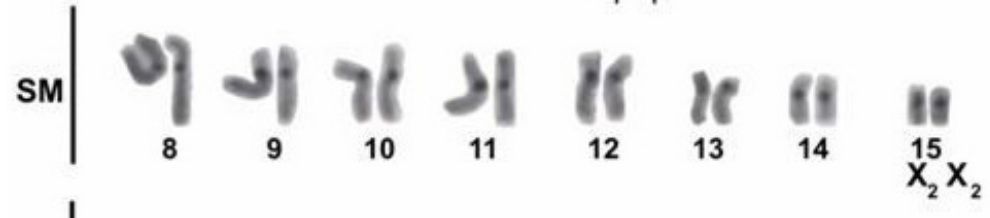
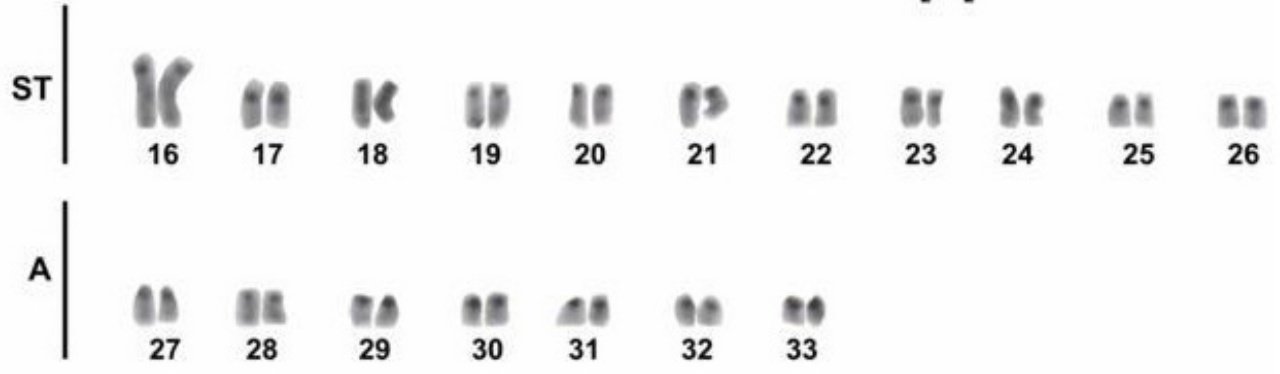

B
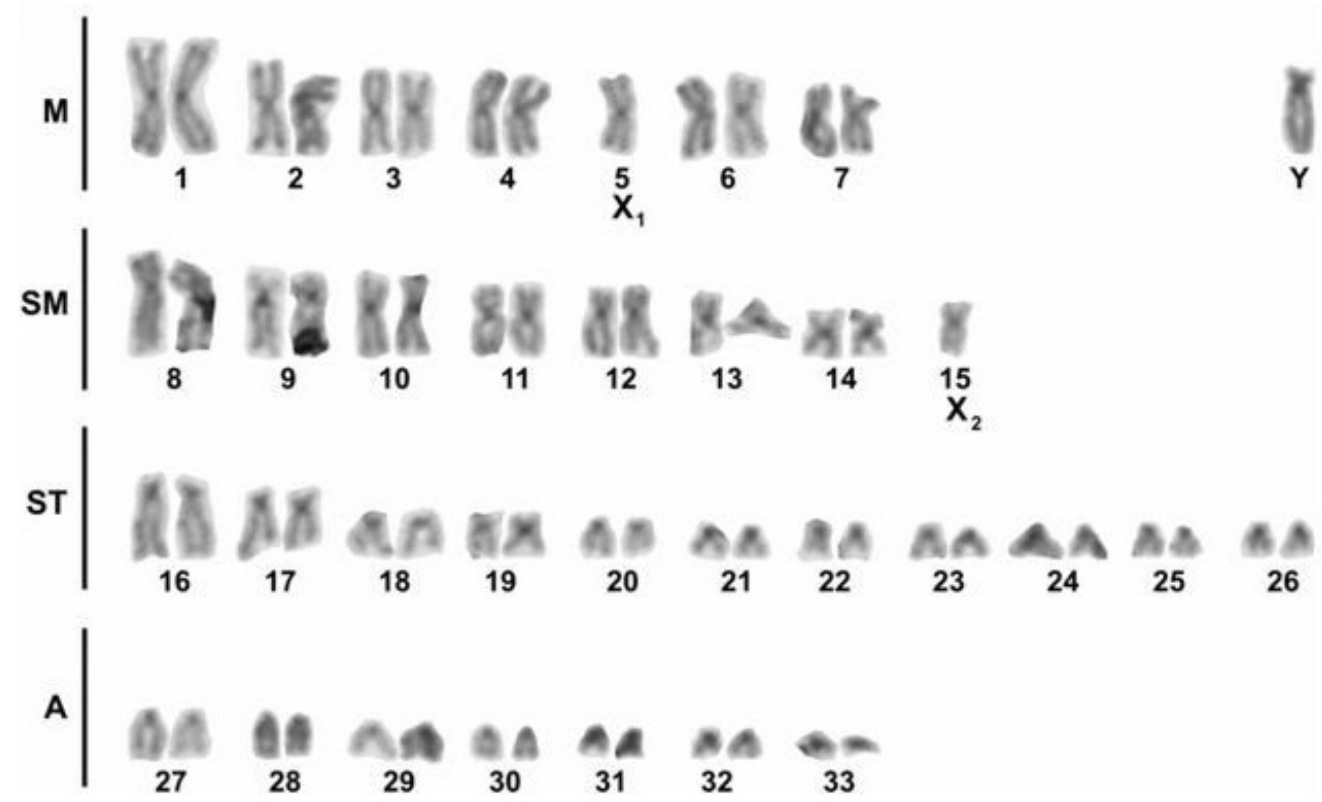

Figure 2. C-banded karyotypes of Potamotrygon motoro. A. Females; B. males. For abbreviations, see legend to Figure 1. 


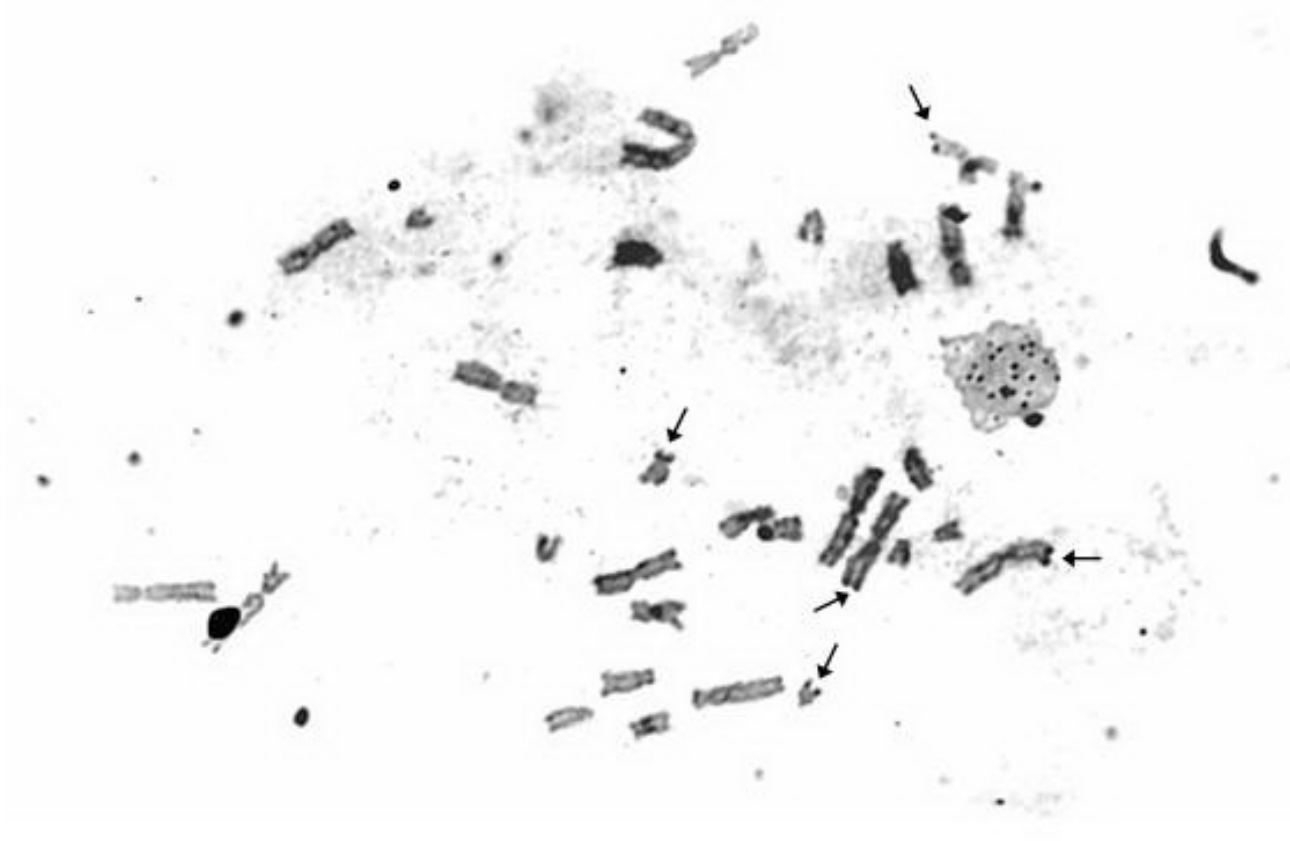

Figure 3. Ag-NOR staining in metaphase chromosomes of Potamotrygon motoro.

\section{DISCUSSION}

The chromosome number of P. motoro $(2 n=65-66)$ is in the range of the diploid numbers described for marine Myliobatiformes $(2 \mathrm{n}=52-78)$. Among Chondrichthyes, only species of Myliobatiformes were reported to have simple systems of sexual determination (Maddock and Schwartz, 1996; Stingo and Rocco, 2001). The high number of bi-armed elements, the presence of sexual chromosomes, and the absence of microchromosomes differentiate this group from the Rajiformes, which exhibit different karyotype features (Stingo and Rocco, 2001). These facts support the phylogenetic classifications proposed by several authors, whereby the Potamotrygonidae family is included in the Myliobatiformes (Mould, 1997; Carvalho et al., 2004; Martin, 2004; Menni, 2004). However, in the species studied of the family Potamotrygonidae, multiple NORs and a pericentromeric C-band pattern are shared as cytogenetic markers (de Valentim et al., 2006; Cruz et al., 2011).

Numerical differences in the karyotype of the 2 sexes and the presence of 3 unpaired chromosomes in the males may indicate the presence of a multiple sex chromosome system $\left(\mathrm{X}_{1} \mathrm{X}_{1} \mathrm{X}_{2} \mathrm{X}_{2} / \mathrm{X}_{1} \mathrm{X}_{2} \mathrm{Y}\right)$ in P. motoro from the Paraná River (Argentina). In the present study, the chromosomes named " $\mathrm{X}_{1}$ " and " $\mathrm{X}_{2}$ " are arbitrarily attributed according to cytological observations and are not associated with an ancestral or derivative X chromosome. Multiple sexual chromosome systems might originate from simple systems because of chromosomal rearrangements between autosome and sexual chromosomes (Bertollo et al., 1997; de AlmeidaToledo et al., 2000a,b; Sánchez et al., 2004). 
In P. motoro from Argentina, the "Y" chromosome might have arisen from translocations of 2 bi-armed chromosomes, one belonging to the 5 th pair $\left(\mathrm{X}_{1}\right)$ and the other belonging to the 15th pair $\left(\mathrm{X}_{2}\right)$. Furthermore, other rearrangements may have arisen through deletions and inversions. Cruz et al. (2011) reported the presence of heteromorphic sex chromosomes in $P$. aff. motoro and P. falkneri, both of which have $2 \mathrm{n}=66$ chromosomes in the females and $2 \mathrm{n}=65$ chromosomes in the males. The authors attributed these cytogenetic differences to heteromorphic sex chromosomes, suggesting the occurrence of a multiple sex chromosome system of the type $\mathrm{X}_{1} \mathrm{X}_{1} \mathrm{X}_{2} \mathrm{X}_{2} / \mathrm{X}_{1} \mathrm{X}_{2} \mathrm{Y}$ in both species. Comparison of these 2 species with the karyotypes and formulae of $P$. motoro from Argentina indicates general minor differences; however, the putative sex chromosomes belong to different categories (M, SM, ST).

de Valentim et al. (2006) cytogenetically described 3 species that belong to 2 genera, $P$. aiereba $(2 \mathrm{n}=90)$, P. motoro $(2 \mathrm{n}=66)$, and P. orbignyi $(2 \mathrm{n}=66)$, from middle Negro River, AM, Brazil; however, the authors found no evidence of sexual heteromorphism. Comparison of the karyotypic data obtained from the current study showed large differences with the Amazonian species, which had a higher number of acrocentric chromosomes. This difference might be attributable to a different interpretation of the cytogenetic results or might have arisen because of different evolutionary pathways. If this suggestion was considered, a taxonomic revision would be necessary because both species studied might belong to different taxonomic entities.

In the cytotype " $\mathrm{D}$ " of Hoplias malabaricus, the $\mathrm{Y}$ chromosome is a clear derivated of chromosomes $\mathrm{X}_{1}$ and $\mathrm{X}_{2}$ (Bertollo, 2007; Cioffi et al., 2010); however, in P. motoro, the "Y" chromosome does not appear to maintain structural similarity with the suggested $\mathrm{X}_{1}$ and $\mathrm{X}_{2}$ chromosomes. Therefore, additional studies by using staining techniques with greater resolution and fluorescence in situ hybridization, with probes obtained by the micromanipulation of chromosomes, would be useful to elucidate the evolution of the heteromorphic sex system.

\section{ACKNOWLEDGEMENTS}

The authors are grateful to Programa de Biologia Pesquera Regional (Universidad Nacional de Misiones, Argentina) for access to facilities during the collection of samples, and to Secretaría de Políticas Universitarias (Ministerio de Educación de la Nación Argentina).

\section{REFERENCES}

Bertollo LAC (2007). Chromosome Evolution in the Neotropical Erythrinidae Fish Family: An Overview. In: Fish Cytogenetics (Pisano E, Ozouf-Costaz C, Foresti F and Kapoor BG, eds.). Science Publishers, Enfield, 195-211.

Bertollo LAC, Takahashi CS and Moreira-Filho O (1978). Cytotaxonomic considerations on Hoplias lacerdae (Pisces, Erythrinidae). Braz. J. Genet. 1: 103-120.

Bertollo LA, Fontes MS, Fenocchio AS and Cano J (1997). The X1X2Y sex chromosome system in the fish Hoplias malabaricus. I. G-, C- and chromosome replication banding. Chromosome Res. 5: 493-499.

Brooks DR, Thorson TB and Mayer MA (1981). Fresh-Water Stingray (Potamotrygonidae) and their Helminth Parasites: Testing Hypotheses of Evolution and Coevolution. In: Advances in Cladistics (Funk VA and Brooks DR, eds.). New York Botanical Garden, New York, 147-175.

Carvalho MR and Lovejoy NR (2011). Morphology and phylogenetic relationships of a remarkable new genus and two new species of Neotropical freshwater stingrays from the Amazon basin (Chondrichthyes: Potamotrygonidae). Zootaxa 2776: 13-48.

Carvalho MR, Lovejoy NR and Rosa RS (2003). Family Potamotrygonidae (River Stingrays). In: Check List of the Freshwater Fishes of South and Central America (Reis RE, Kullander SO and Ferraris CJ, eds.). PUCRS, Porto Alegre, 22-28.

Carvalho MR, Maisey JG and Grande L (2004). Freshwater stingray of the Green River Formation of Wyoming (early 
Eocene), with the description of a new genus and specie and analysis of its phylogenetic relationships (Chondrichthyes, Myliobatiformes). Am. Museum Nat. Hist. 284: 1-136.

Castex MN (1964). Estado actual de los estudios sobre la raya fluvial neotropical. Rev. Mus. Prov. Cienc. Nat. F. Ameghino Cincuentenario: 9-49.

Cioffi MB and Bertollo LA (2010). Initial steps in XY chromosome differentiation in Hoplias malabaricus and the origin of an $\mathrm{X}_{1} \mathrm{X}_{2} \mathrm{Y}$ sex chromosome system in this fish group. Heredity 105: 554-561.

Cruz VP, Shimabukuro-Dias CK, Oliveira C and Foresti F (2011). Karyotype description and evidence of multiple sex chromosome system $\mathrm{X}_{1} \mathrm{X}_{1} \mathrm{X}_{2} \mathrm{X}_{2} / \mathrm{X}_{1} \mathrm{X}_{2} \mathrm{Y}$ in Potamotrygon aff. motoro and P. falkneri (Chondrichthyes: Potamotrygonidae) in the upper Paraná River basin, Brazil. Neotrop. Ichthyol. 9: 201-208.

de Almeida-Toledo LF, Daniel-Silva MF, Lopes CE and Toledo-Filho SA (2000a). Sex chromosome evolution in fish. II. Second occurrence of an $\mathrm{X}_{1} \mathrm{X}_{2} \mathrm{Y}$ sex chromosome system in Gymnotiformes. Chromosome Res. 8: 335-340.

de Almeida-Toledo LF, Foresti F, Daniel MF and Toledo-Filho SA (2000b). Sex chromosome evolution in fish: the formation of the neo-Y chromosome in Eigenmannia (Gymnotiformes). Chromosoma 109: 197-200.

de Valentim FC, Falcão JN, Porto JI and Feldberg E (2006). Chromosomes of three freshwater stingrays (Rajiformes Potamotrygonidae) from the Rio Negro basin, Amazon, Brazil. Genetica 128: 33-39.

Fenocchio AS and Bertollo LAC (1988). A simple method for Fresh-water fish lymphocyte culture. Rev. Brasil. Genet. 11: 847-852.

Guerra MS (1986). Reviewing the chromosome nomenclature of Levan et al. Rev. Brasil. Genet. 9: 741-743.

Howell WM and Black DA (1980). Controlled silver-staining of nucleolus organizer regions with a protective colloidal developer: a 1-step method. Experientia 36: 1014-1015.

López HL, Morgan CC and Montenegro MJ (2002). Ichthyological ecoregions of Argentina. Serie Documents ProBiota $1-68$.

López HL, Miquelarena AM and Menni RC (2003). Lista comentada de los peces continentales de la Argentina. Serie Técnica y Didáctica ProBiota 1-85.

Lovejoy NR (1996). Systematics of myliobatoid elasmobranches: with emphasis on the phylogeny and historical biography of Neotropical freshwater stingrays (Potamotrygonidae: Rajiformes). Zool. J. Linn. Soc. 117: 207-257.

Maddock MB and Schwartz FJ (1996). Elasmobranch cytogenetics: methods and sex chromosomes. Bull. Mar. Sci. 58: 147-155.

Martin RA (2004). Evolution and Zoogeography of Freswaters Elasmobranches with Notes on their Conservation. In: Biology an Conservation of Freshwater Elasmobranchs. Symposium Proccedings (Martin RA and MacKinlay D, eds.). International Congress on the Biology of Fish, Manaus, 1-14.

Martinez-Achenbach G and Valentinis MAS (1976). Notas acerca de algunas especies de raya fluvial (Batoidei, Potamotrygonidae), que frecuentan el Sistema Hidrográfico del río Paraná Medio en el Departamento La Capital (Santa Fe - Argentina). Com. Mus. Prov. Cienc. Nat. F. Ameghino 8: 1-34.

Menni RC (2004). Zoogeografía de los Peces Marinos. In: Sistemática y Filogenia de los Vertebrados con Énfasis en la Fauna Argentina (Montero R and Autino A, eds.). Universidad Nacional de Tucumán, Tucumán, 69-77.

Mould B (1997). Classification of the Recent Elasmobranchii. A classification of the Living Sharks and Rays of the World. Available at [http://ibis.nott.ac.uk/elasmobranch/corelas2.pdf]. Accessed January 9, 2013.

Nelson JS (1994). Fishes of the World. 3rd edn. John Wiley and Sons, New York.

Oliveira C, Foresti F and Hilsdorf AW (2009). Genetics of neotropical fish: from chromosomes to populations. Fish. Physiol. Biochem. 35: 81-100.

Rosa RS, Castello HP and Thorson TB (1987). Plesiotrygon iwamae, a new genus and species of neotropical freshwater stingray. Copeia 2: 447-458.

Sánchez S, Laudicina A and Jorge LC (2004). A new report of multiple sex chromosome system in the order Gymnotiformes (Pisces). Cytologia 69: 155-160.

Silva JPCB and Carvalho MR (2011). A new species of Neotropical freshwater stingray of the genus Potamotrygon Garman, 1877 from the Río Madre de Díos, Peru (Chondrichthyes: Potamotrygonidae). Pap. Avulsos Zool. 51: 139-154.

Stingo V and Rocco L (1991). Chondrichthyan cytogenetics: a comparison with teleosteans. J. Molec. Evol. 33: 76-82.

Stingo V and Rocco L (2001). Selachian cytogenetics: a review. Genetica 111: 329-347.

Sumner AT (1972). A simple technique for demonstrating centromeric heterochromatin. Exp. Cell Res. 75: 304-306. 